\title{
MOVIMENTOS SOCIAIS: REVISITANDO A PARTICIPAÇÃO E A INSTITUCIONALIZAÇÃO
}

\section{EUZENEIA CARLOS}

Este artigo analisa os efeitos da inserção institucional em arranjos participativos sobre os padrões de ação coletiva de movimentos sociais, no que se refere à formação organizacional, relacional e discursiva dos atores. As transformações nos movimentos sociais foram examinadas a partir da comparação intertemporal de seus padrões de ação ao longo de três décadas (1980-2010), mediante instrumentos metodológicos do método qualitativo (análise documental e entrevista em profundidade) e quantitativo (survey). O estudo comparado da Federação das Associações de Moradores da Serra e do Centro de Defesa de Direitos Humanos da Serra, localizados no Espírito Santo, demonstra que movimentos institucionalmente inseridos combinam: 1. complexificação da estrutura organizacional e participação dos militantes; 2. relações com instituições políticas e outros movimentos ou entidades não institucionais e 3. interações cooperativas e contestatórias na relação sociedade-Estado.

Palavras-chave: movimentos sociais, participação, institucionalização, complexificação organizacional, interações cooperativas.

Recebido: 03/06/2010 Aprovado: 05/09/2011

\section{SOCIAL MOVEMENTS: REVISITING THE PARTICIPATION AND INSTITUTIONALIZATION}

This article examines the effects of participatory arrangements in the institutional context on patterns of collective action of social movements regarding to organizational, relational and discursive structures. The changes in the social movements were examined from the inter-temporal comparison of their patterns of action over three decades (1980-2010), by methodological tools of qualitative methods (document analysis and 
in-depth interview) and quantitative (survey). The comparative study of the Federation of Neighborhood Associations of Serra and Center for the Defense of Human Rights of Serra, located in Espirito Santo, shows that movements institutionally embedded combine 1.complexity of the organizational structure and participation of militants, 2.relations with political institutions and movements or other non-institutional entities and 3.cooperative and contestatory interactions in the relationship society-state.

Keywords: social movements, participation, institutionalization, organizational complexity, cooperative interactions. 


\section{MOVIMENTOS SOCIAIS: REVISITANDO A PARTICIPAÇÃO E A INSTITUCIONALIZAÇÃO}

Euzeneia Carlos

No contexto posterior à Constituinte de 1988, a multiplicação de instituições participativas de elaboração de políticas públicas propiciou novas oportunidades de participação e representação no desenho das políticas e na regulação da ação governamental (Houtzager, Gurza Lavalle e Acharya, 2004; Avritzer, 2002; Dagnino, 2002). A inserção institucional de movimentos e organizações sociais nas experiências inovadoras como o Orçamento Participativo (OP) e os conselhos gestores, por um lado, ampliou as arenas de acesso à institucionalidade política e, por outro, desafiou os atores coletivos para novas práticas e relações com o Estado.

A preocupação central deste artigo é inquirir acerca das implicações desse engajamento institucional sobre um ator em especial: os movimentos sociais que emergiram no contexto de transição do regime autoritário e, posteriormente, ocuparam espaços de mediação institucional na relação Estado-sociedade. Esses movimentos são aqui compreendidos como coletividades formadas por uma pluralidade de atores sociais, organizacionais e institucionais ligados em modelos de interação, com base em identidades comparti- 
lhadas construídas através de relações de conflito e cooperação (Melucci, 1996; Diani, 1992).

Nesse contexto, quais efeitos a inserção institucional dos atores societários e o desenho das instituições de participação produzem sobre os padrões de ação coletiva de movimentos sociais engajados nesses espaços? No mesmo sentido, quais mudanças os movimentos sociais,constituídos no bojo do processo de redemocratização do país, vivenciaram em decorrência de seu engajamento em instituições participativas, no que tange as dimensões organizacional, relacional e discursiva da ação coletiva?A denominação "padrões de ação coletiva” (doravante PACs) corresponde a modalidades de ações organizacionais, relacionais e discursivas, as quais orientam o comportamento dos movimentos como atores políticos face às instituições e ao Estado em geral. Naturalmente, é difícil pensar num padrão homogêneo ou num modelo de ação, que representaria os atores 316 societários e que servisse de paradigma da ação dos movimentos, tendo em vista a complexidade e heterogeneidade da sociedade civil (Dagnino, Olvera e Panfichi, 2006).

Este estudo busca estabelecer debate crítico com as teorias de movimentos sociais que supõem uma separação entre estes e a política institucionalizada, e que analisam a ação coletiva a partir de estruturas dicotômicas: contenção-institucionalização, outsider-insider, autonomia-cooptação. Tais teorias explicam as implicações da inserção de atores coletivos em instituições políticas a partir da ideia de institucionalização do movimento social, cujo enfoque estritamente organizacional é associado à desmobilização, burocratização, profissionalização e descolamento da base social (Meyer e Tarrow, 1998; Piven e Cloword, 1979; McCarthy e Zald, 1973). No entanto, o pressuposto desses teóricos de correlação entre complexificação organizacional e desmobilização do movimento, desconsidera os incentivos gerados à participação pelo desenho inovativo das instituições participativas. 
E, por outro lado, a compreensão dos efeitos do engajamento institucional sobre os movimentos, restrita ao seu núcleo organizacional, desprivilegia outras dimensões da ação coletiva - como a relacional e a cultural - imprescindíveis à compreensão dos PACs em contextos de interação com a institucionalidade política.

Parte-se do pressuposto que a relação entre movimentos sociais e instituições políticas é contingente e mutuamente constitutiva, cujas implicações ou efeitos decorrentes são produzidos sobre ambos os atores societários e institucionais (Skocpol, 1992). Essa perspectiva, conduz ao reconhecimento da complexidade dos movimentos e a variação nos PACs, os quais podem combinar elementos contraditórios da relação sociedade-Estado, ao contrário de constituírem modelos puros, coerentes e estáveis.

Em linhas gerais, este artigo demonstra que a inserção institucional de movimentos produz efeitos sobre as dimensões organizacional, relacional e discursiva da ação coletiva. No que se refere ao elemento organizacional, o exame da estrutura funcional, das estratégias de ação e das dinâmicas de participação do movimento, evidenciou processos de complexificação organizacional, os quais são combinados à participação dos militantes no processo decisório. A composição da estrutura relacional dos movimentos também sofre deslocamentos, no sentido da ampliação dos vínculos com instituições políticas, especialmente órgãos do governo, ao mesmo tempo em que combina a relação com outros movimentos e entidades sociais não institucionais. O engajamento dos atores coletivos em instituições participativas, por sua vez, é acompanhado por processos de reelaboração e ressignificação discursiva acerca da relação sociedade-Estado, caracterizados por linguagens de cooperação e contestação. Em torno dessas principais argumentações está estruturado o artigo, precedidas, naturalmente, de breves considerações metodológicas e do aporte teórico. 


\section{Considerações metodológicas}

Este artigo é oriundo de pesquisa de doutorado em andamento,conduzida através do método comparativo de estudo de casos (Peters, 1998; George e Bennett, 2004) aplicado a dois movimentos sociais localizados no município da Serra, região metropolitana do Espírito Santo, no período de 1980 a 2010, a saber: Federação das Associações de Moradores da Serra (Fams) e Centro de Defesa de Direitos Humanos da Serra $(\mathrm{CDDH})^{1}$.

A análise comparativa dos movimentos foi processada em dois níveis: 1) comparação intertemporal (cross-time), e 2) comparação entre os casos (cross-case). A comparação cross-time das trajetórias ao longo de um continuum intertemporal de três décadas, considerou a variação nos PACs em dois contextos analíticos, denominados Tempo 1 (T1) e Tempo 2 (T2).Compreende o T1 o contexto de redemocratização da década de 1980 e, o T2,o período de criação das 318 instituições participativas nos governos, sobretudo a partir de 1990. A comparação cross-case, por sua vez, possibilitou a verificação das regularidades nos PACs, ao mesmo tempo em que dimensionou as variações e heterogeneidades na ação dos movimentos.

A análise das regularidades e variações nos PACs, em ambos os níveis de comparação, foi controlada por uma compreensão completa dos casos, favorecida por perspectiva multi-method que conduziu a um desenho de pesquisa que combinou instrumentos do método qualitativo e quantitativo,

\footnotetext{
${ }^{1}$ A pesquisa da tese envolveu, ainda, outros dois movimentos localizados na cidade de Vitória-ES, qual seja, o Conselho Popular de Vitória (CPV) e a Associação Capixaba de Proteção ao Meio Ambiente (Acapema). Cabe ressaltar que, o trabalho de campo foi viabilizado pelo financiamento parcial do Fundo de Apoio à Ciência e Tecnologia do Município de Vitória-ES (Facitec), desenvolvido no período de fevereiro a setembro de 2010. Agradeço aos pesquisadores de aperfeiçoamento e de iniciação científica que participaram dessa etapa do doutoramento, desenvolvida no Laboratório de Estudos Políticos (LEP) da Universidade Federal do Espírito Santo (Ufes), especialmente a Carla Rocha Sousa, Leonardo Holanda Nascimento, Cícero Frechiani Linhalis e Bruno Fernandes Medeiros.
} 
a saber: 1) pesquisa documental ${ }^{2}$ no acervo das organizações de movimentos; 2) entrevista em profundidade com atores-chave (militantes e ex-militantes); e 3) survey de questionário semiestruturado $^{3}$ aplicado a 52 militantes selecionados por meio de amostra não aleatória, que considerou a posição de centralidade do ator no movimento. Na análise geral, os dados provenientes dos variados instrumentos metodológicos foram agrupados em torno de temas, a fim de verificar a triangulação das evidências e promover a validação dos resultados a partir de linhas convergentes de investigação.

\section{Movimentos sociais e instituições políticas: limites do aporte teórico}

A relação entre movimentos sociais e instituições políticas requer uma compreensão dinâmica que acentue os aspectos de coconstituição entre sociedade e Estado, como esferas que interagem e se influenciam mutuamente em um processo contínuo e circunstancial, cujas fronteiras são imprecisas e enevoadas (Skocpol, 1992; Somers, 1993). Essa perspectiva é particularmente relevante à análise de movimentos institucionalmente inseridos (institutionally embedded ${ }^{4}$ ), na medida em que concebe sociedade e Estado como produto de um processo dinâmico e contingente de mútua

\footnotetext{
${ }^{2} \mathrm{O}$ arquivo de documentação é composto por estatutos sociais, regimentos, certidões, legislações, livros de atas de reuniões, livros de assinaturas de reuniões, atas de eleições de diretoria, atas de congressos, boletins e jornais próprios, relatórios, planejamentos, projetos, dentre outros. Esses dados somam cerca de 300 documentos, os quais foram analisados por meio da técnica de análise de conteúdo e sistematizados em banco de dados do Excel.

${ }^{3} \mathrm{O}$ questionário de survey é composto por 72 questões, entre formato fechado (36), aberto (29) e semiaberto (7), tendo tido sua primeira versão base no survey da pesquisa "Associativismo e Representação Popular: comparações entre a América Latina e a Índia”, desenvolvida pelo Centro Brasileiro de Análise e Planejamento (Cebrap) e Institute of Development Studies Sussex (IDS), com a coordenação de Adrian Gurza Lavalle e Peter Houtzager. O processamento e análise dos dados do survey foram realizados através do programa estatístico SPSS 17.0.

${ }^{4}$ No dizer de Peter Evans, 1995. Ver também Houtzager, Gurza Lavalle e Acharya (2004).
} 
constituição. As teorias de movimentos sociais $^{5}$ que analisam a sociedade e o Estado a partir de categorias estanques, autônomas e dicotômicas são, nesse sentido, limitadas à explicação dos efeitos das interações entre atores societários e institucionais sobre os PACs de movimentos sociais.

Grosso modo, predomina nessas teorias a acepção de movimento como protesto público e participação outsider (extrainstitucional), cuja chave analítica impõe-nos duas implicações: (i) dificulta o reconhecimento das interações mutuamente constitutivas entre o movimento e o sistema político (agências do governo, partidos políticos e o Estado) e da combinação circunstancial entre modalidades de ação outsider e insider (intrainstitucional) e (ii) interpreta o engajamento em instituições políticas como decorrente de um processo de institucionalização do movimento que afeta, exclusiva e homogeneamente, a dinâmica organizacional da ação coletiva. A perspectiva cíclica e dicotômica dessa abor320 dagem desconsidera as mudanças e reconfigurações na ação coletiva ao longo do tempo, assim como, a capacidade dos movimentos em combinar elementos contraditórios e híbridos na relação sociedade-Estado.

Ao contrário dessa concepção que identifica movimentos sociais como protesto e ação outsider, severos estudos acerca da interpenetração entre movimentos e instituições têm refutado a tese que distingue o movimento como estratégia extrainstitucional, sob o argumento de que muitos movimentos interagem, constitui relações e formam alianças com partidos políticos, igrejas, agências do Estado e poder judiciário. Embora alguns movimentos se identifiquem como revolucionários claramente outsiders e oposi-

\footnotetext{
${ }^{5}$ Essas teorias são comumente descritas como pertencentes à escola norte-americana (teoria de mobilização de recursos e teoria do processo político) e ao paradigma europeu de ação coletiva (teoria dos novos movimentos sociais). Embora não sejam necessariamente excludentes, cada uma delas desenvolveu uma estrutura de análise própria (Melucci, 1996; Della Porta e Diani, 2006).
} 
tores às instituições estabelecidas, muitos outros mantêm relações ativas com atores políticos e institucionais, em diferentes contextos históricos e em processos dinâmicos de coconstituição $^{6}$. Os movimentos sociais, assim, não estão fixados por princípio a uma forma de ação determinada (Raschke, 1994), podendo desenvolver, circunstancialmente, diferentes PACs e combiná-los de forma muito multivariada - protestos públicos, ações formais e alianças com políticos, partidos e agências do Estado.

De fato, a fronteira entre política não institucionalizada e institucionalizada é pouco clara (Goldstone, 2003), e a permeabilidade entre ambas as esferas exaure de sentido a distinção dual entre movimento outsider e movimento insider defendido pelas perspectivas dicotômicas da ação coletiva. Certos movimentos, transcendendo as delimitações de um evento específico, reúnem diferentes ocorrências, manifestações e práticas de atores individuais, organizacionais e institucionais ao longo do tempo, em cuja trajetória desenvolvem a habilidade de combinar padrões contraditórios de ação, como a contestação e a cooperação na relação sociedade-Estado. Essas práticas dos atores do campo movimentalista num continuum intertemporal não significam, necessariamente, a persistência dos mesmos elementos representativos dos PACs de um contexto específico, mas a permanente reelaboração e ressignificação contextualizada.

A caracterização do movimento social como fenômeno cíclico e extrainstitucional, tende a conceber o engajamento societário nas instituições políticas como decorrente de um processo de institucionalização do movimento que afeta sua dinâmica organizacional, como dito no início desta

\footnotetext{
${ }^{6}$ No Brasil, estudos que enfocam a relação entre setores progressistas da igreja católica e movimentos sociais, no período de transição do regime autoritário, podem ser encontrados em Doimo (1995) e Sader (1988); a relação entre movimentos sociais e o PT em Sader (1988); e a interação entre o movimento estudantil e o PT em Mische (2008).
} 
sessão. A ideia de institucionalização do movimento, examinada mais detidamente pela teoria do processo político, é defendida nos seguintes termos:

O padrão de institucionalização é quase o mesmo em todo lugar: à medida que acaba o entusiasmo da fase disruptiva de um movimento e a política se torna mais hábil em exercer o controle, os movimentos institucionalizam suas táticas e tentam obter benefícios concretos para seus apoiadores através de negociação e acordo - um caminho que frequentemente é bem-sucedido ao custo de transformar o movimento em um partido ou grupo de interesse (Tarrow, [1998] 2009, p. 134).

De acordo com o autor, a integração do movimento às estruturas da institucionalidade política corresponde a mudanças no repertório de confronto, decorrente do desdobramento interno de ações contenciosas, que é análoga a 322 institucionalização do movimento social. Embora com limitada comprovação empírica, a institucionalização é definida como "a criação de um processo repetitivo que é essencialmente autossustentável, no qual todos os atores relevantes possam recorrer a rotinas bem-estabelecidas e familiares" (Meyer e Tarrow, 1998, p. 21). Institucionalização, nessa visão, compreende três componentes principais: 1. rotinização da ação coletiva - ativistas e autoridades aderem a um script comum e modelo previsível de ação; 2. inclusão e marginalização - ativistas institucionalmente orientados são recompensados com o acesso ao sistema político, enquanto aqueles determinados a desafios mais abrangentes e a evitar o compromisso inerente à política institucional se arriscam a repressão ou marginalização e 3. cooptação - ativistas modificam suas reivindicações e táticas para que possam perseverar dentro da política institucional. O termo institucionalização, por fim, é remetido à profissionalização do movimento, quer dizer, as habilidades relativas à organiza- 
ção e à comunicação entre os ativistas dos movimentos se tornam cada vez mais profissionais, cuja expansão afeta o "modelo de representação política fundado no contato com as bases representadas" (Tarrow, [1998] 2009, pp. 21-22).

Essa noção opera sem introduzir uma distinção que lhe é fundamental entre a institucionalização do canal de mediação com o Estado e aquela do movimento. E, ao não fazê-lo, estabelece uma relação causal mecânica e unívoca entre institucionalização da mediação e ado ator coletivo. Torna-se, portanto, inábil para objetar em que medida a primeira gera características institucionais no comportamento do ator, assim como, de captar as regularidades e variações na relação instituições e atores sociais. Por esse motivo, este estudo não assume, a priori, que a institucionalização do canal de mediação gera a do movimento, e abre à verificação empírica os efeitos daquela sobre os PACs, pois, entre outras razões, o movimento pode ser altamente organizado, formalizado e profissionalizado também nos ciclos de protesto público, mesmo que sob o manto de narrativas de espontaneidade.

Em particular, o enfoque no núcleo organizacional do movimento conduziu a uma visão estreita de institucionalização definida em termos de complexificação institucional, a qual é remetida à rotinização, previsibilidade, formalização, profissionalização e desmobilização. Essa perspectiva, por um lado, desconsiderou a diferenciação nos padrões organizacionais, tendo em vista as possibilidades de combinação entre complexificação organizacional e mobilização, em processos de engajamento em instituições inovadoras. Por outro lado, dimensões complementares na configuração dos movimentos são ignoradas, como as dinâmicas relacionais e suas possibilidades de pluralização das redes sociais e institucionais, e os elementos discursivos da ação com seus deslocamentos e ressignificações da relação sociedade-Estado. 


\section{Os movimentos sociais em foco: emergência einserção institucional}

A Fams emergiu em 1980, com a finalidade de organizar, coordenar e fortalecer o movimento de bairro e reivindicar melhorias sociais e urbanas ao poder público. Ela contou com ampla rede de relações sociais em sua formação política e organizacional, como Comunidades Eclesiais de Base (CEBs), partidos políticos de esquerda, como o Partido dos Trabalhadores (PT), sindicatos trabalhistas, comissões de direitos humanos, grupos de mulheres e de jovens, Equipe de Apoio aos Movimentos Populares e ONGs, como a Federação de Órgãos para Assistência Social e Educacional (Fase) e o Centro de Educação e Comunicação Popular Dom João Batista (Cecopes). Autodenominada "movimento popular", possui uma estrutura federativa com 125 associações de moradores e suas principais realizações correspondem a setores de políticas públicas nas áreas de saúde, infraestrutura urbana, transporte coletivo,

324 educação, moradia e meio ambiente, além da implementação de instituições participativas na gestão pública.

Já o CDDH surgiu em 1984, como movimento de coordenação da ação mobilizadora de outros movimentos sociais e organizações civis, atuando na defesa dos direitos humanos universais e fomentando a criação de associações, sindicatos e outras formas de organização popular, em nível municipal e estadual. O CDDH foi inicialmente criado como comissão de direitos humanos da igreja católica e composto por integrantes das CEBs e militantes de movimentos locais, sobretudo sindicatos trabalhistas e associações de moradores. O CDDH promoveu diversas ações unificadas entre forças sociais e políticas, articulando com o Conselho Pastoral de Carapina (Copaca), a Fams, o PT, sindicatos, ONGs e outros movimentos de direitos humanos, tendo alcançado conquistas em políticas sociais voltadas à criança e adolescente, violência, saúde, educação, moradia e na criação de instituições participativas no governo. 
As novas oportunidades de participação na elaboração das políticas e no controle da ação governamental que emergiram da criação de instituições participativas, inauguraram um cenário de inserção de movimentos sociais em instituições do Estado e de relação direta com agências governamentais. No município da Serra-ES, essas esferas institucionalizadas de participação foram introduzidas a partir de 1997, pela coligação partidária PDT-PT-PSB que elegeu Sérgio Vidigal para a gestão 1997-2000 e segue por quatro mandatos consecutivos (1997 a 2012) ${ }^{7}$.

As instituições de participação, então criadas, passaram a ocupar centralidade na dinâmica cotidiana dos movimentos analisados. Especificamente, a Fams atua, em nível municipal, em duas esferas institucionais de mediação da relação sociedade-Estado: os conselhos gestores de políticas e o OP. Nos 16 conselhos existentes, a Fams concentra a maioria dos assentos destinados a representantes da sociedade civil, nas áreas de saúde, educação, assistência social, habitação, segurança, meio ambiente, entre outros, além das conferências setoriais. A Fams coordena programas governamentais de participação social, como a instalação anual do OP na Assembleia Municipal do Orçamento (AMO) e do Plano Diretor Municipal Participativo (PDMP).

$\mathrm{O} \mathrm{CDDH}$, por sua vez, se engaja nas instituições do Estado através da participação em conselhos gestores, comitês, comissões especiais e na gestão de programas. Em nível municipal, o CDDH participa de oito conselhos de políticas e nas conferências setoriais, nas áreas de saúde, assistência social, segurança alimentar, gênero, entre outros. E, em nível estadual, no Conselho Estadual de Direitos Humanos, no Conselho Estadual de Gestão de Segurança Pública e

\footnotetext{
7 No período de transição do regime autoritário e redemocratização, a Serra foi governada por políticos remanescentes das oligarquias rurais que se revezaram no poder de 1977 a 1996 - José Maria Miguel Feu Rosa (PDS-ARENA e PMDB) e João Baptista da Motta (PMDB e PSDB).
} 
no Comitê de Enfrentamento a Tortura, além de participar da gestão de programas governamentais, como o Programa de Proteção a Vítimas e Testemunhas de Crimes (Provita), o Programa de Proteção a Criança e ao Adolescente Ameaçada de Morte (PPCAM) e Programa de Proteção aos Defensores de Direitos Humanos (PPDDH).

A relevância do engajamento em instituições participativas é reconhecida por $93 \%$ dos militantes da Fams e 95\% dos ativistas do $\mathrm{CDDH}^{8}$, para os quais a importância da participação nos órgãos do governo reside na garantia da representação da sociedade civil na elaboração de políticas públicas, no exercício da participação cidadã e na vocalização dos interesses das coletividades em políticas sociais. Para eles, a validade da inserção institucional do movimento está, ainda, no potencial de democratização do processo decisório, de accountability dos gestores governamentais e de eficiência nos gastos públicos.

\section{Trajetória e complexificação organizacional}

Movimentos sociais institucionalmente inseridos complexificam a estrutura organizacional, especializam a dinâmica funcional e formalizam as estratégias de ação, ao mesmo tempo em que mantém a participação dos militantes no processo decisório.

\section{Especializando a estrutura funcional}

A preocupação com a organização da ação coletiva esteve presente na Fams e no CDDH desde sua gênese. O processo organizacional desses movimentos veio acompanhado de certa dose de formalização, através do incentivo a medidas formais que foram sendo incorporadas paulatinamente ao cotidiano

\footnotetext{
8 Os termos "militantes" e "ativistas" são utilizados como sinônimos, para designar os participantes em posição de tomadores de decisões. No caso da Fams, esses correspondem aos membros da diretoria, do colegiado, delegados do congresso e lideranças das associações de moradores filiadas. No CDDH, são membros da coordenação diretora e membros filiados da assembleia.
} 
das atividades, como a elaboração e registro do estatuto social e regimento interno, o registro de atas e presenças e o cadastro dos associados. No entanto, a formalização era concebida em seu amplo significado, como integrante do processo de organização das entidades e do alcance da legitimidade diante do poder público, quer dizer, não como mero formalismo ou apego a burocracia, mas como instrumento de democracia interna, descentralização e vínculo com as bases.

Na Fams, a estrutura organizacional foi constituída pelos seguintes órgãos: coordenação geral, colegiado, conselho fiscal, assessoria e comissões de trabalho. A coordenação geral constituía o órgão executivo, composto pelo coordenador e vice-coordenador, primeiro e segundo secretário, primeiro e segundo tesoureiro. O órgão máximo de deliberação era o colegiado, composto pelos membros da coordenação e três delegados de cada associação de moradores, instância onde as principais decisões quanto ao plano de lutas eram tomadas e se concretizava o processo eleitoral interno. $\mathrm{O}$ órgão assessoria era formado por membros da Equipe de Assessoria aos Movimentos Populares da Serra ${ }^{9}$,que atuavam no assessoramento e educação política do movimento. As comissões temáticas constituíam um órgão temporário da estrutura organizacional, formadas para operacionalizar e executar os trabalhos deliberados ${ }^{10}$. Esse desenho organizacional vigorou durante os cinco primeiros anos, tendo sido posteriormente reestruturado e conduzido o movimento nos dez anos seguintes.

A estrutura organizacional da Fams, a partir de 1986, preservou o núcleo de coordenação geral e introduziu duas

\footnotetext{
${ }^{9}$ A Equipe de Apoio na Serra era formada por professores e estudantes da Ufes que atuaram na formação política de movimentos populares, especialmente, na década de 1980.

${ }^{10}$ A organização das atividades de associações e movimentos através de comissões temáticas é tributária da experiência vivenciada pelos militantes nas CEBs, cujo desenho descentralizado da organização era operacionalizado através da criação de comissões e grupos de trabalho (Doimo, 1995).
} 
novas instâncias de deliberação - o congresso e as coordenações de áreas. O congresso passou a órgão máximo de deliberação, com periodicidade bianual e instituído para avaliar os rumos do movimento, traçar novas diretrizes e plano de luta e eleger a coordenação. Participam do congresso os membros do colegiado, da coordenação executiva, das coordenações de áreas e doze representantes de cada associação filiada. As coordenações de áreas correspondem à representação das associações por área definida com base em referências territoriais. Nesse formato, a assessoria política foi suprimida enquanto órgão permanente e seus antigos membros compuseram a coordenação geral do movimento, no I Congresso em 1986.

Nova reestruturação organizacional da Fams ocorreu em 1996, cujas principais mudanças foram aprofundadas nas reedições dos estatutos sociais de 2003 e 2008. As transformações organizacionais nos movimentos, no período pós328 1996, se inserem no bojo de severas mudanças no contexto político local, haja vista a eleição de governos convergentes com o discurso de participação e que implementaram os novos arranjos institucionais. De modo geral, essas transformações remetem a um processo de complexificação organizacional, caracterizado por especialização funcional e formalização das estratégias de ação.

No processo de especialização funcional da Fams, maior especificação foi conferida aos órgãos mediante a criação de novos organismos e de melhor precisão nas atribuições dos mesmos. Somando-se a essa dinâmica, em 2003, a mudança do regime de coordenação geral para presidência e a criação de secretarias populares de políticas públicas, nas áreas de educação, meio ambiente, segurança e saúde. Nesse contexto de inserção institucional, os novos órgãos visam especializar a estrutura funcional da Fams à participação nos canais participativos de políticas públicas, ao acompanhamento das atividades dos conselheiros muni- 
cipais e delegados do OP e a ampliação de sua atuação em setores que favorecem maior conhecimento sobre o funcionamento da máquina pública. Esse amoldamento da estrutura funcional do movimento à funcionalidade do Estado conduz os atores coletivos à discussão de políticas públicas de modo mais enfático, algo notadamente caro em se tratando de associações tradicionalmente afeitas a reivindicações pontuais e concretas.

A especialização da estrutura funcional da Fams veio acompanhada pela absorção de profissionais temporários e remunerada no interior da organização, os quais não participam das assembleias deliberativas e voltam-se ao suporte técnico e jurídico nas áreas de secretaria, comunicação, contabilidade e advocacia. Com efeito, a comunicação com os militantes passou a combinar o contato pessoal e formal, e a organização das atividades passou a ter o apoio técnico de profissionais nos assuntos de políticas públicas, gerenciamento de programas governamentais e elaboração de projetos de captação de recursos para contratos, convênios e termos de parceria com órgãos públicos e privados ${ }^{11}$.

Na trajetória de formação organizacional do CDDH, por sua vez, as alterações estatutárias de impacto substantivo ocorreram em 2000 e 2003, as quais também conduziram a maior especialização funcional. Em sua gênese, a estrutura funcional do movimento de direitos humanos fora constituída por três órgãos: diretoria executiva, conselho fiscal e assembleia geral. A diretoria era composta pelo presidente e vice-presidente, primeiro e segundo secretário, primeiro e segundo tesoureiro e comissões temáticas. O órgão máximo de deliberação é a assembleia geral, formada pela diretoria, conselho fiscal e todos os membros filiados e reunidos mensalmente.

\footnotetext{
${ }^{11}$ No intuito de ampliar seus instrumentos legais de captação de recursos financeiros, a Fams requereu a qualificação como Organização da Sociedade Civil de Interesse Público (Oscip), em 2003, através da Lei 9.790/99 que estabeleceu novo marco legal para repasse de recursos governamentais para as entidades sociais.
} 
Como na Fams, as comissões temáticas constituem um órgão temporário da estrutura funcional, criadas na finalidade de auxiliar os trabalhos da diretoria e motivadas pelo ideal de descentralização do planejamento e execução das atividades, imprimido pela CEBs. Formação política, violência, moradia, alfabetização e comunicação eram as temáticas mais recorrentes na criação das comissões, tendo sido duas delas tornadas permanentes na reformulação estatutária de 1993, a saber, secretaria de comunicação e secretaria para assuntos de cidadania e violência.

O processo de especialização do $\mathrm{CDDH}$ envolveu alteração na estrutura funcional, incorporação de novos objetivos e novas fontes de autossustentação financeira. Nessas mudanças introduzidas na década finda, a diretoria foi transformada em um conselho diretor composto por cinco coordenações (geral, adjunto, financeiro, formação e cidadania e comunicação), ao qual se somaram os órgãos 330 outrora existentes, como conselho fiscal, assembleia geral e comissões temporárias. O CDDH manteve a assembleia anual para elaboração do plano de ação, chamada Programação Anual de Atividades, e a assembleia bianual para eleição do conselho diretor e conselho fiscal.

A mudança nos objetivos do $\mathrm{CDDH}$ não expressa transformações no projeto político do passado, mas uma ampliação dos objetivos direcionada à inclusão de novos segmentos sociais e a incorporação de novas atividades na defesa dos direitos humanos. Primeiro, a ampliação de questões de defesa de direitos humanos para incluir definições mais amplas de exclusão social e de inclusão de novos grupos sociais tradicionalmente excluídos, como os afrodescendentes, quilombolas e LGBT. E, segundo, o desenvolvimento de atividades voltadas à elaboração e gestão de políticas públicas nas áreas de justiça, segurança, educação, saúde e assistência social. Novos mecanismos voltados à autossustentação financeira do movimento também foram estabelecidos, como convênios, 
cooperação técnica com órgãos governamentais e não governamentais e o Termo de Parceria, a partir de sua qualificação como Oscip, em 2000.

A especialização organizacional do CDDH também é caracterizada pela absorção temporária de profissionais remunerados para apoio técnico e jurídico aos trabalhos desenvolvidos, como advogados, administradores, contadores, assistentes sociais e psicólogos. Como na Fams, esses profissionais não participam das deliberações dos militantes e os impactos diretos na organização do movimento incidem sobre dois aspectos: a comunicação entre os militantes passou a combinar o contato informal e formal e, a participação na elaboração de políticas, na gestão de programas governamentais e na captação de recursos a contar com suporte técnico e jurídico.

\section{Formalizando as estratégias de ação}

Movimentos sociais possuem a habilidade de combinar uma pluralidade de formas de ação que perpassam estratégias contenciosas ou disruptivas, ações formais de encaminhamento de demandas, e alianças com partidos políticos, políticos e ex-lideranças do movimento. A combinação entre essas formas de ação é contingente e dinamizada pela relação sociedade-Estado de cada contexto histórico.

Nos movimentos Fams e CDDH, essa diversidade de estratégias de ação foram combinadas ao longo do tempo, percorrendo conjunturas de transição do autoritarismo político e de restabelecimento das instituições democráticas. Mesmo que cada era histórica tenha sua forma predominante de ação, os ativistas direcionavam suas reivindicações e proposições ao poder público fazendo uso de canais múltiplos e complementares: abaixo-assinado, manifesto, manifestação pública, passeata, ato público, vigília, ofícios, ação judicial, reuniões com autoridades, apoio de partidos, políticos e ex-lideranças, e outras (Tabela 1). 
No contexto de transição do autoritarismo e redemocratização da década de 1980, os movimentos estudados desenvolveram estratégias de mobilização coletiva que ilustraram verdadeiro "ciclo de protesto público" (Tarrow, 1997), frente ao não reconhecimento pelas autoridades públicas e não acesso às instituições políticas, especificamente: passeatas, manifestações, exposições de faixas, mutirões, peças teatrais, dramatizações, atos públicos, plebiscitos, abaixo-assinados, denúncias à imprensa e ocupação de área pública (Tabela 1). Na percepção dos militantes, as estratégias contenciosas eram relevantes para o êxito das reivindicações, visibilidade do movimento, chamar a atenção das autoridades, mobilizar os participantes, apoio da imprensa e opinião pública, e vocalizar as demandas.

A trajetória de ambos os movimentos testemunhou mudanças severas nestas estratégias de ação, visíveis mais enfaticamente a partir da última década.Com a redemocratização 332 do país, o acesso às instituições políticas e a implementação de esferas participativas nas agências dos governos, o uso de estratégias formais no encaminhamento das deliberações ao poder público tornaram-se predominantes. Por um lado, a redução das atividades de protesto público (contention) e, por outro, a expansão de ações formais (ofícios a órgãos públicos e audiências com autoridades) evidenciam transformações nas estratégias de ação em direção a repertórios rotinizados e previsíveis, que contrastam com o ciclo de mobilizações e caracterizam um processo de formalização das estratégias de ação (Tabela 1).

Os militantes argumentam que no contexto de engajamento em instituições participativas e de mudanças nas relações com o governo, os mecanismos de ação formais conferem legalidade às suas demandas e são importantes no encaminhamento das reivindicações. Ademais, esse procedimento é visto como estratégia adequada ao estabelecimento de um canal de diálogo com o governo e ao reconhecimento do movimento enquanto interlocutor legítimo. 
Tabela 1

Atividades utilizadas pela Fams e CDDH no encaminhamento de reivindicações e propostas ao poder público, ao longo do tempo.

\begin{tabular}{|l|r|r|r|r|}
\hline \multirow{2}{*}{ Respostas } & \multicolumn{2}{c|}{ Fams } & \multicolumn{2}{c|}{ CDDH } \\
\cline { 2 - 5 } & 1980 s & 2000 s & 1980 s & 2000 s \\
\hline Encaminhar ofícios e cartas a órgãos públicos & $60,7 \%$ & $78,6 \%$ & $75,0 \%$ & $91,3 \%$ \\
\hline $\begin{array}{l}\text { Encaminhar ação judicial ou projeto de lei de } \\
\text { iniciativa popular }\end{array}$ & $42,9 \%$ & $28,6 \%$ & $33,3 \%$ & $78,3 \%$ \\
\hline $\begin{array}{l}\text { Realizar reuniões ou audiências com } \\
\text { autoridades públicas }\end{array}$ & $67,9 \%$ & $92,9 \%$ & $66,7 \%$ & $95,7 \%$ \\
\hline Solicitar o apoio de políticos eleitos aliados & $46,4 \%$ & $50,0 \%$ & $29,2 \%$ & $56,5 \%$ \\
\hline Solicitar o apoio de partidos políticos aliados & $42,9 \%$ & $46,4 \%$ & $33,3 \%$ & $52,2 \%$ \\
\hline $\begin{array}{l}\text { Solicitar o apoio de ex-lideranças que ocupam } \\
\text { cargos públicos }\end{array}$ & $25,0 \%$ & $35,7 \%$ & $4,2 \%$ & $52,2 \%$ \\
\hline $\begin{array}{l}\text { Fazer abaixo-assinado, manifesto ou carta } \\
\text { aberta à população }\end{array}$ & $71,4 \%$ & $35,7 \%$ & $87,5 \%$ & $65,2 \%$ \\
\hline $\begin{array}{l}\text { Fazer manifestação pública, passeata e } \\
\text { ocupação de área pública }\end{array}$ & $85,7 \%$ & $25,0 \%$ & $87,5 \%$ & $52,2 \%$ \\
\hline $\begin{array}{l}\text { Fazer ato público, vigília ou jejum } \\
\text { Total de respondentes }\end{array}$ & $42,9 \%$ & $10,7 \%$ & $79,2 \%$ & $43,5 \%$ \\
\hline
\end{tabular}

Fonte: Survey da Pesquisa "Movimentos sociais e instituições políticas", 2010. Nota: resposta múltipla.

Cabe ressaltar que, ao longo da trajetória dos movimentos, apenas uma das categorias de estratégia de ação permaneceu relativamente estável- solicitar apoio de partidos políticos e políticos -, embora essa não tenha sido predominante em nenhum dos dois períodos comparados (Tabela 1). Assim, o suporte de partidos, políticos e de ex-lideranças do movimento em cargos do governo constitui estratégia relevante em distintos cenários político-institucionais, tendo permanecido com pouca variação na Fams e aumentado no CDDH. Na percepção dos ativistas, a solicitação de apoio 
da elite política (ideologicamente alinhada ao movimento) é importante para o alcance dos resultados das ações, por facilitar o encaminhamento das reivindicações e o acesso aos órgãos públicos.

Não obstante a formalização das estratégias de ação seja traço predominante nos PACs de ambos os movimentos, algumas variações nos repertórios do contexto de engajamento institucional são irrefutáveis, como a maior habilidade do CDDH em combinar de modo mais equilibrado o uso de ações formais ou institucionais com o uso de ações diretas ou contenciosas para o encaminhamento de suas demandas ao poder público ${ }^{12}$.

\section{Combinando complexificação organizacional e mobilização dos participantes}

Nas teorias de movimentos sociais, a complexificação organizacional do movimento é frequentemente associada à 334 burocratização, desradicalização, desmobilização e descolamento das bases sociais, como dito.Esses estudos interpretam a incorporação de ações dos movimentos nos contextos institucionais como rotinizada e despolitizada e pressupõe uma oposição entre movimentos e instituições políticas que é inoperante para explicar a ação de atores societários no contexto de engajamento institucional (Katzenstein, 1998).

A análise da trajetória da Fams e CDDH e de seu engajamento em instituições participativas demonstra que os movimentos mudam ao longo do tempo, mas não que se transformam em organizações tradicionais, com estruturas burocráticas e liderança centralizada. Em outras palavras, o movimento institucionalmente inserido não depende, necessariamente, de organizações grandes, burocráticas e oligárquicas, isto, pois o próprio pode combinar um modelo alta-

\footnotetext{
${ }^{12}$ Evidências de movimentos sociais que combinam, no contexto democrático, estratégias formalizadas e disruptivas de ação para encaminhar demandas ao poder público podem também ser encontradas em Tatagiba (2009) e Feltran (2010).
} 
mente complexo e formalizado com uma dinâmica de mobilização e participação dos militantes no processo decisório.

Esse aparente paradoxo pode ser explicado pela especificidade dos arranjos participativos onde se inserem tais movimentos, os quais se diferem das instituições tradicionais por inovarem o formato institucional, combinando mecanismos de participação direta e representativa na elaboração de políticas públicas (Santos e Avritzer, 2002). Nesse sentido, as instituições participativas geram novas oportunidades de participação no desenho das políticas para grupos tradicionalmente excluídos do processo político, que favorecem a mobilização dos atores coletivos no contexto de inserção institucional.

A despeito do declínio das atividades contenciosas, como protestos, passeatas e ocupações, as instituições participativas incentivaram o surgimento de novas associações de moradores e o revigoramento da vida associativa, conforme demonstrado por Avritzer (2002) e Baiocchi (2005). No caso da Fams, o número de associações de moradores triplicou no período de 1996 a 2007, saltando de 43 para 125 entidades filiadas.

O contexto de engajamento institucional também ampliou e diversificou as esferas públicas de mobilização dos movimentos, os quais passaram a combinar a participação em conselhos gestores, orçamentos participativos, conferências municipais, programas governamentais e fóruns de outras entidades e movimentos, com a atuação no interior de suas próprias organizações, em reuniões, assembleias e congressos. A percepção dos ativistas da Fams e CDDH de acúmulo de novas atividades de participação, como representante nos conselhos gestores, delegado no OP, participante em seminários, fóruns e palestras sobre políticas públicas, são evidências de participação e engajamento social, ao invés de denotar um contexto de não participação, desmobilização e descolamento social. Por outro 
lado, a conjugação de múltiplas atividades nas novas esferas tem levado a sobrecarga de muitos ativistas e a redução da frequência das reuniões no interior da organização de ambos os movimentos. Em muitas situações, por conta do tempo reduzido, os ativistas concentram sua militância nas instituições participativas, em prejuízo da organização do movimento, para participar de reuniões internas.

Neste sentido, embora seja fato que os movimentos não se desmobilizaram, também é verdadeiro que o tempo para encontros internos foi impactado e a periodicidade das reuniões da diretoria e da assembleia foi reduzido, se comparado à dinâmica dos anos 1980. A diminuição do impacto das assembleias sobre a tomada de decisão, planejamento e execução das atividades também são observados, sendo a percepção de participação nessas ações maior no contexto de emergência do movimento. Porém, medidas de descentralização ainda permanecem predominantes, especialmen-

336 te em três aspectos: 1) na percepção dos ativistas de que, na maioria das vezes, participam das principais decisões, e que, quase sempre, participam do planejamento e da execução das atividades; 2) no trabalho de acompanhamento das associações de moradores e 3) na realização periódica de assembleia geral e congresso.

Em suma, o engajamento em instituições participativas possibilita a conjugação de elementos, supostamente contraditórios, na dinâmica do movimento - complexidade organizacional e mobilização -, na medida em que produz incentivos para a pluralização de esferas de deliberação que pressupõe a participação dos militantes no processo decisório.

\section{Interações cooperativas na relação sociedade-Estado}

Movimentos sociais institucionalmente inseridos pluralizam a rede de relações sociais, aumentando os vínculos com instituições governamentais e desenvolvendo interações cooperativas na relação sociedade-Estado, ao mesmo tempo em que mantém a relação com 
outros movimentos e entidades não institucionais e estabelecem, circunstancialmente, interações contestatórias com o Estado.

As transformações nos PACs dos movimentos sociais, ao longo de suas trajetórias, ocorrem em um contexto histórico de ressignificação das concepções e discursos acerca da relação sociedade-Estado, quer dizer, em face de um processo de "interação dinâmica e mutuamente constitutiva de identidades, discursos e práticas" (Alvarez et al., 2003, p. 543). A configuração política do município da Serra-ES de meados dos anos 1990 em diante, contextualiza esse processo de ressignificação discursiva e de mudanças nas relações dos movimentos com o Estado e as instituições políticas em geral, que contrasta com a concepção pretéritado período de transição do regime autoritário da década de 1980. $\mathrm{Na}$ época de emergência dos movimentos, a relação com o governo é descrita pelos militantes da Fams e CDDH mediante categorias de conflito (oposição e conflito, denúncia e pressão, divergência ideológica, cobrança), marginalização (não relação, não reconhecimento pelo governo, não acesso aos órgãos públicos, não atendimento das reivindicações) e repressão (ameaças e repressão pelo governo). Nesse contexto, as práticas coletivas de oposição e enfrentamento aos poderes constituídos eram motivadas pelo discurso de movimento autônomo e independente das instituições políticas e do Estado.

Com a institucionalização da participação nas agências governamentais e o estabelecimento de nova concepção de relação com o Estado, as categorias de conflito e oposição cederam espaço às categorias de cooperação, colaboração, parceria e diálogo, permanecendo a autonomia nas relações e negociações travadas com o governo como um ideal nem sempre realizado. Em ambos os movimentos, os militantes identificam as interações com o governo como de parceria e cooperação, proximidade e diálogo, como enfatizado nas falas: 
Parceria. É isso, a gente caminha lado a lado, dialogando e sempre tentando atender às demandas do município, que são muitas.

Parceria. O poder público respeita muito a Federação e tem uma parceria com o poder público para esclarecer.

[...] A relação agora é boa, existe um diálogo, eles chamam a gente para conversar.

[...] Tem sido muito boa, uma relação de parceria. Esse governo de hoje é o governo que nós queríamos na década de 1980, mais democrático, mais atencioso com a gente. Nos sentimos responsáveis pelo governo de hoje.

[...] Boa, uma relação aberta de transparência, de parceria nas discussões e busca de soluções em conjunto ${ }^{13}$.

O discurso de cooperação com a esfera estatal veio acompanhado de significativa mudança na estrutura da rede de relações dos movimentos, mediante o aumento dos vínculos relacionais com instituições governamentais, identificado por $93 \%$ dos militantes da Fams e $91 \%$ do CDDH. Comparativamente ao contexto de fundação, os movimentos sociais institucionalmente inseridos pluralizam a rede de relações sociais, na medida em que incorporam às conexões com instituições partidárias e religiosas, movimentos e entidades sociais,novos laços com as agências do Estado. Nesse contexto de inserção institucional e de diversificação da rede de relações sociais, os movimentos se engajam em interações cooperativas com o Estado, estabelecendo rela-

\footnotetext{
${ }^{13}$ Depoimentos de militantes da Fams extraídas do survey da pesquisa "Movimentos sociais e instituições políticas”, em 2010.
} 
ções de colaboração e parceria na elaboração e implementação de políticas públicas ${ }^{14}$. Quais as motivações para o estabelecimento de interações cooperativas entre Estado e a sociedade civil? O que o movimento social ganha e o que perde com a cooperação com o governo? As relações cooperativas entre sociedade civil e Estado eliminaram o conflito e a contestação? Vejamos.

As motivações para interações cooperativas na relação sociedade-Estado podem ser encontradas em dois fatores interdependentes: na relação histórica dos movimentos com os partidos políticos no poder e na absorção da proposta de participação pelo governo. Os movimentos sociais da Serra construíram vínculos orgânicos e ideológicos com partidos políticos de esquerda, particularmente o PT, em um processo de simbiose e coconstituição conduzido por ativistas multifiliados aos movimentos e ao partido, que foi extremamente influente na gênese de ambos. As relações de cunho ideológico e político-partidário entre movimentos e partidos conduziram ao apoio político da Fams e do CDDH às candidaturas do PT, nos pleitos eleitorais de 1982, 1989, 1992 e 1996, para o executivo local.

Nos três primeiros processos eleitorais do período de transição democrática, o PT perdeu as eleições para políticos tradicionais do município que se revezavam no poder - José Maria Feu Rosa e João Baptista da Motta. E, no pleito de 1996, o PT perdeu as eleições para o candidato do PDT Sérgio Vidigal, apoiado por coligação partidária que reunia antigos aliados do Partido dos Trabalhadores, como o PPS (antigo PCB) e o PSB. Nas competições eleitorais seguintes, o PT deixou de apresentar candidatura própria e passou, juntamente com o PSB, a constituir aliança partidária com o PDT. Os movimentos sociais, por sua vez, estenderam o

\footnotetext{
${ }^{14}$ Evidências empíricas de relações cooperativas entre sociedade civil e Estado no contexto de inserção institucional foram também encontradas por Wampler (2007) e Baiocchi (2005).
} 
apoio político-partidário ao PT à aliança então firmada PDT-PT-PSB -, abrindo caminho para o estabelecimento de relações de colaboração e de cooperação com o Executivo municipal na elaboração de políticas públicas.

O processo eleitoral de 1996 guarda ainda um significado simbólico para os militantes de ambos os movimentos, qual seja, de finalização de uma era de autoritarismo, corrupção e clientelismo nos rumos da vida política local. Segundo uma ativista da Fams,esse momento político

representou, de fato, um parâmetro entre duas fases distintas da política da Serra: o tempo do 'abacaxi' com seu coronelismo agrário, de voto de cabresto e a que ele [Sérgio Vidigal] representou, de instituição e avanço da democracia participativa e popular na gestão pública da Serra (Jornal da Fams, 2009, p. 7).

340 Para os movimentos, essa mudança representava a absorção de reivindicações históricas na agenda política, especialmente quanto a gestão participativa na administração pública; haja vista suas inúmeras iniciativas ao longo do período de 1982 a 1996 de implementação de canais institucionalizados de participação, todas malogradas.

Essa percepção de correlação entre a ascensão do grupo político no poder local e a instituição da democracia participativa é o segundo elemento motivador da cooperação na relação sociedade-Estado. A adoção de instituições participativas de políticas públicas pelo governo sinalizou para os movimentos que relações de diálogo, cooperação e parceria deveriam ser estabelecidas entre ambos, ao revés do passado de enfrentamento e oposição. Nesse novo contexto, o movimento deixou de ser caracterizado como ator e âmbito para a confrontação dialética e passou a perceber-se como instância para o diálogo e a colaboração com aqueles com os quais pode alcançar resultados efetivos para suas ações. 
Mas, o que o movimento social ganha e o que perde com relações de cooperação com o governo? A percepção dos ativistas da Fams e CDDH é que a construção de relações de parceria e colaboração com o governo favorece o resultado das ações do movimento, na medida em que atores coletivos alcançam o reconhecimento da legitimidade de seus reclamos e de sua atuação como representante de grupos amplos da sociedade e possuem acesso às instituições políticas. Para eles, a relação de parceria e cooperação com o governo é relevante ao atendimento das reivindicações do movimento, ao estabelecimento do diálogo e proposição, à representação e participação nas instituições participativas, à gestão de programas e convênios governamentais, e ao acesso às agências governamentais. Em outras palavras, vínculos relacionais colaborativos têm como consequência o atendimento de demandas históricas do movimento e sua influência política na agenda pública.

Nesse contexto de engajamento institucional, se, por um lado, o estabelecimento de interações cooperativas na relação sociedade-Estado é necessário à influência política do movimento, através das quais militantes obtém adequado acesso ao ambiente institucional e aos agentes governamentais; por outro, a ampliação dessa influência depende da habilidade dos atores coletivos em combinar relações de cooperação e de autonomia com o governo. Isto, pois, o exacerbamento da cooperação pode gerar o excesso de comprometimento e vínculos institucionais do movimento com o Estado, reduzindo sua potencial capacidade de pressão e influência e favorecendo a dependência dos atores coletivos. Motivo pelo qual a cooperação na relação sociedade-Estado deve vir acompanhada por significativa autonomia política, de modo a configurar equilibradamente interações cooperativas autônomas.

Os militantes dos movimentos analisados são unânimes em reconhecer que relações colaborativas com o governo os expõem a riscos diversos que dificultam um comportamento crítico e autônomo. Assim, autodefinem os riscos a que estão 
expostos no contexto de participação institucional: risco de atrelamento e cooptação, dependência e submissão, perda da autonomia, distanciamento da base social, impedimento de ações contrárias e críticas, perda da capacidade de discussão e proposição e de vinculação da imagem do movimento com a do governo. Naturalmente, a consciência dos militantes de que relações de proximidade e cooperação com o Estado oferecem riscos de dependência e perda de autonomia não significa necessariamente que assim o são, ou que modelos cooperativos na relação sociedade-Estado são dependentes a priori. Isso significaria partir de uma compreensão homogênea da ação coletiva que desconsidera a diversidade das configurações sociais e as possibilidades de invenção criativa, como o fazem as combinações dicotômicas - cooperação-cooptação e contestação-autonomia.

Os movimentos analisados apresentam divergências internas e entre si na matéria autonomia. Grosso modo, os 342 militantes do movimento de direitos humanos se autopercebem como autônomos de modo mais consistente (não contraditório ou ambíguo), comparativamente aos militantes do movimento de associações de moradores, os quais divergem entre si e apontam ambas as categorias - autonomia e dependência. A relação de autonomia com o Estado é exposta por militante do CDDH:

Embora tenhamos relação de convênio, estamos conseguindo manter uma autonomia política que eu acho que pouquíssimas entidades do país conseguiram. Ou seja, ainda que os recursos adivinhem do governo, ele não interfere na nossa ação, ele não interfere na condução das nossas políticas, ele não interfere nos nossos posicionamentos. Mas, não é porque ele não queira, é porque nós não permitimos ${ }^{15}$.

\footnotetext{
${ }^{15}$ Depoimento de militante do CDDH em entrevista realizada a 18/08/2010.
} 
Correlação clara verifica-se entre o movimento que se autopercebe autônomo nas interações de cooperação com o Estado e aquele que desenvolve habilidades em combinar formas criativas de ação e negociação política, voltadas ao equilíbrio entre a estabilidade e previsibilidade das estratégias institucionalizadas e o ambiente instável e incerto produzido por ações disruptivas ou contenciosas. O CDDH representa um movimento que combina essas duas modalidades de ação oriundas de lógicas contraditórias - cooperação e contestação - configurando um "modelo híbrido de ação" cujas partes são acionadas circunstancialmente no contexto histórico e político. O CDDH desenvolve um modelo de ação que combina ações formalizadas (ofícios a órgãos públicos, audiências com autoridades políticas e ação judicial) com estratégias de mobilização pública (protesto, passeata, ato público, vigília, abaixo assinado e manifesto), ao passo que a Fams reduziu significativamente suas ações disruptivas e tornou preponderante iniciativas institucionalizadas de ação, como demonstrado na Tabela 1 .

A habilidade do CDDH em mesclar cooperação e contestação verifica-se ainda nas estratégias para introdução do plano de lutas nos órgãos do governo, pois a depender das circunstâncias políticas os atores coletivos ora são conduzidos à cooperação e formação de alianças com o governo e com partidos políticos coligados, ora seu reverso, ou seja, são guiados para contestação e oposição ao governo e neutralidade em relação aos partidos políticos da base aliada governamental. As relações cooperativas e contestatórias com o Estado são assim narradas:

Uma relação de independência e autonomia, sendo que às vezes apóia e outra critica.

É uma relação institucional, às vezes contra o governo com denúncias e colaboração através de convênio. 
Uma relação de troca, em que há um convênio, há uma participação do CDDH em conselhos, por exemplo, mas não é de conivência, havendo conflito também.

Sobretudo de cobrança e de denúncia, mesmo se com alguns integrantes dos governos municipais e estadual tem colaboração.

É um diálogo necessário, conveniente, de proteção aos direitos humanos na sociedade em geral, inclusive contra o governo, o que torna a relação conflitante ${ }^{16}$.

Pode-se inferir que, os padrões híbridos de ação conferem maior poder de influência e pressão aos movimentos sobre os governos, na medida em que, acionado de modo circunstancial, criam um ambiente mais instável e incerto 344 para a negociação política que é particularmente importante no contexto de engajamento em instituições e de cooperação nas relações com o Estado. Na trajetória do movimento de direitos humanos, as iniciativas híbridas de ação possibilitaram a pluralização das arenas para a participação e entendimentos políticos, na medida em que o movimento considera a multiplicidade de esferas públicas para atuação, sejam espaços institucionais ou não institucionais.

Em suma, as transformações nos PACs dos movimentos sociais são configuradas no bojo de processos de ressignificação da relação sociedade-Estado, a qual passou a caracterizar interações cooperativas com o governo. Os níveis de acesso dos movimentos às instituições governamentais, a realização de suas demandas e influência política vinculam-se ao estabelecimento dessas interações cooperativas com

\footnotetext{
${ }^{16}$ Depoimentos de militantes da Fams extraídas do survey da pesquisa "Movimentos sociais e instituições políticas”, em 2010.
} 
a esfera governamental, as quais se estabelecem no plano político-ideológico e podem se estender ao partidário-eleitoral. Em complemento, a comparação entre os casos indica que, a combinação entre interações cooperativas e contestatórias no sistema de relações sociedade-Estado, aos moldes de um modelo híbrido de ação, é capaz de ampliara influência dos atores societários na agenda política.

\section{À guisa de conclusão}

O engajamento de movimentos sociais em instituições participativas produz consequências sobre os PACs, os quais apresentam regularidades quanto a um processo de complexificação organizacional, caracterizado por formatação peculiar que combina o aumento da especialização da estrutura funcional e da formalização das estratégias de ação à manutenção de dinâmicas participativas que garantem a mobilização dos militantes no processo decisório. Essas transformações organizacionais dos movimentos são configuradas no contexto de ressignificação da concepção de relação sociedade-Estado, num processo onde práticas e discursos interagem dinamicamente e se coconstituem. Na reconfiguração dessas relações sociedade-Estado, uma nova concepção a respeito da relação com o Estado e as instituições é forjada, onde os movimentos percebem a construção de interações cooperativas com os governos como favoráveis à influência na agenda política, ao atendimento de suas demandas históricas e ao acesso aos órgãos públicos.

Os PACs dos movimentos sociais no contexto democrático, por outro lado, também apresentam variações que remetem a emergência de modelos de ação híbridos que combinam na relação sociedade-Estado interações cooperativas e contestatórias, voltadas a tensionar a estabilidade e previsibilidade das estratégias institucionalizadas e a ampliar a influência na agenda política. As oportunidades de pluralização das esferas públicas de ação dos movimentos, ou seja, 
a conjugação entre o engajamento em instituições e arenas não institucionalizadas de participação, por sua vez, pode ampliar as redes de relações do movimento e ativar um campo diversificado de atores em interação, espaços públicos e territórios de negociação que incidem positivamente sobre a configuração de interações sociedade-Estado ancorada no árduo equilíbrio entre cooperação e autonomia.

\section{Euzeneia Carlos}

é doutoranda em ciência política pela USP e professora do Departamento de Ciências Sociais da Ufes.

\section{Referências Bibliográficas}

ALVAREZ, S. et al. 2003. "Encontrando os feminismos latino-americanos e caribenhos”. Estudos Feministas, v. 11, n. 2, pp. 541-575.

AVRITZER, L. 2002. "Modelos de deliberação democrática: uma análise do orçamento participativo no Brasil”. In: SANTOS, B. S. (org.) Democratizar a democracia participativa: os caminhos da democracia participativa. Rio de Janeiro: Civilização Brasileira.

BAIOCCHI, G. 2005. Militants and citizens: the politics of participatory democracy in Porto Alegre. Stanford: Stanford University Press.

DAGNINO, E. (org.) 2002. Sociedade civil e espaços públicos no Brasil. São Paulo: Paz e Terra.

; OLVERA, A.; PANFICHI, A. 2006. "Para uma leitura da disputa pela construção democrática na América Latina”. In: (orgs.)

A disputa pela construção democrática na América Latina. São Paulo: Paz e Terra, pp. 13-91.

DELLA PORTA, D.; DIANI, M. 2006. Social movements: an introduction. Oxford: Blackwell.

DIANI, M. 1992. "The concept of social movement". The Sociological Review, v.40, n.1, pp.1-25.

DOIMO, A. 1995. A vez e a voz do popular. movimentos sociais e participação política no Brasil pós-70. Rio de Janeiro: Anpocs/Relume Dumará.

EVANS, P. 1995. Embedded autonomy: states and industrial transformation.

Princeton: Princeton University Press.

FELTRAN, G. 2010. "Margens da política, fronteiras da violência: uma ação coletiva das periferias de São Paulo”. Lua Nova, n. 79, pp. 201-233. GAMSON, W. 1990. The strategy of social protest. Belmont: Wadsworth. 
GEORGE, A. L.; BENNETT, A. 2004. Case studies and theory development in the social sciences. Cambridge: MIT Press.

GOLDSTONE, J. 2003. "Bridging institucionalized and noninstitucionalized politics". In: (org.). States, parties, and social movements. Cambridge: Cambridge University Press.

GURZA LAVAlle, A.; HOUTZAGER, P.; CASTEllo, G. [no prelo]. “A construção política das sociedades civis”. In: (org.). O horizonte da política: questões emergentes e agendas de pesquisa. São Paulo: Ed. da Unesp.

\section{e sociedade civil”. Lua Nova, n. 67, pp.49-103.}

HELLER, P. 2005. "Reinventing public power in the age of globalization. Decentralization and the transformation of movement politics in Kerala”. In: RAY, R; KATZENSTEIN, M. F. (orgs.) Movement social in India: poverty, power, and politics - Asia/Pacific/Perspectives. Lanham: Rowman \& Littlefield.

HOUTZAGER, P.; GURZA LAVALLE, A.; ACHARYA, A. 2004. "Atores da sociedade civil e atores políticos. Participação nas novas políticas democráticas em São Paulo”. In: AVRITZER, L. (org.) Participação em São Paulo. São Paulo: Ed. da Unesp, pp. 257-322.

KATZENSTEIN, M. F. 1998. "Stepsisters: feminist movement activism in different institutional spaces". In: MEYER, D. \& TARROW, S. (orgs.) The social movements society: contentious politics for a new century. Lanham: Rowman \& Littlefield, pp. 195-216.

McADAM, D; TARROW, S.; TILLY, C. 2001. Dynamics of contention. Cambridge studies in contentious politics. Cambridge: Cambridge University Press.

McCARTHY, J.; ZALD, M. 1973. The trends of social movements in America: professionalization and resource mobilization. Morristown: General Learning Press.

MELUCCI, A. 1996. Challenging codes. Cambridge/New York: Cambridge University Press.

MEYER, D.; TARROW, S. (orgs.). 1998. The social movement society: contentions politics for a new century. Lanham: Rowman \& Littlefield.

MISCHE, A. 2008.Partisan publics: communication and contention across Brazilian youth activist networks. Princeton: Princeton University Press. OFFE, C. 1990. "Reflections on institutional self-transformation of movement politics: a tentative stage model”. In: DALTON, R. \& KUECHLER, M. (orgs.). Challenging the political order: new social and political movements in Western democracies. New York: Oxford University Press. 
PETERS, B. G. 1998. Comparative politics: theory and methods. New York: New York University Press.

PIVEN, F. F.; CLOWARD, R. 1979. Poor people's movements: why they succeed and how they fail. New York: Vintage Books.

RASCHKE, J. 1994. Sobre el concepto de movimiento social. Zona Abierta, n. 69, pp. 121-134.

SADER, E. 1988. Quando novos personagens entram em cena. Experiências, falas e lutas dos trabalhadores da Grande São Paulo (1970-80). São Paulo: Paz e Terra.

SANTOS, B. S.; AVRITZER, L. 2002. "Para Ampliar o cânone democrático”. In: SANTOS, B. S. (org.). Democratizar a democracia: os caminhos da democracia participativa. Rio de Janeiro: Civilização Brasileira.

SKOCPOL, T. 1992. Protecting soldiers and mothers: the political origins of social policy in the United States. Cambridge: Belknap Press/Harvard University Press.

SOMERS, M. R. 1993. "Citizenship and the place of the public sphere: law, community, and political culture in the transition to democracy". American Sociology Review, v. 58, pp. 587-620.

348 TARROW, S. 1997. El poder en movimiento: los moví
acción colectiva y la política. Madri: Alianza. 2009 [1998]. O poder em movimento: movimentos sociais e confronto político. Petrópolis: Vozes.

TATAGIBA, L. 2009. "Desafios da relação entre movimentos sociais e instituições políticas. O caso do movimento de moradia da cidade de São Paulo - Primeiras reflexões”. Colombia Internacional, v. 71, pp. 63-83.

TILLY, C. 2004. Social movements, 1768-2004. Boulder/London: Paradigma. WAMPLER, B. 2007. Participatory budgeting in Brazil: contestation, cooperation, and accountability. University Park: Pennsylvania State University Press. 